\title{
METAL COMPLEXES WITH TWO DIFFERENT SULFUR CONTAINING LIGANDS-II*
}

\author{
J. G. M. VAN DER LINDEN \\ Department of Inorganic Chemistry, University of Nijmegen, Toernooiveld, Nijmegen, \\ The Netherlands
}

(Received 9 August 1971)

\begin{abstract}
The synthesis and characterization of a series of mixed 1,1-/1,2-dithiolene complexes, $M\left[\mathrm{~S}_{2} \mathrm{C}_{2}(\mathrm{CN})_{2}\right]\left[\mathrm{S}_{2} \mathrm{CNR}_{2}\right]^{z}$ with $z=-1, M=\mathrm{Ni}, \mathrm{Cu}, \mathrm{Pd}, \mathrm{Pt}$ and with $z=0, M=\mathrm{Ni}, \mathrm{Cu}, \mathrm{Au}$, $M\left[\mathrm{~S}_{2} \mathrm{C}_{2}(\mathrm{CN})_{2}\right]\left[\mathrm{S}_{2} \mathrm{CNCN}\right]^{2-}, M=\mathrm{Ni}, \mathrm{Pd}$, and $\mathrm{Ni}\left[\mathrm{S}_{2} \mathrm{C}_{2}(\mathrm{CN})_{2}\right]\left[\mathrm{S}_{2} \mathrm{COC}_{2} \mathrm{H}_{5}\right]^{-}$are reported. Voltammetric studies in dichloromethane revealed that the mixed complexes could be oxidized in a one electron step, the half-wave potentials of which were generally in the middle between those for the unmixed complexes. The $\mathrm{C}-\mathrm{N}$ stretching frequencies observed in the i.r. spectra of the $M\left[\mathrm{~S}_{2} \mathrm{C}_{2}(\mathrm{CN})_{2}\right]\left[\mathrm{S}_{2} \mathrm{CNR}_{2}\right]^{z}$ complexes are reported.
\end{abstract}

\section{INTRODUCTION}

THERE is a growing interest in metal complexes containing two different sulfur donor ligands, especially those with the 1,1- and 1,2-dithiolato ligand systems. Nickel bis-complexes with two different 1,2-dithiolato ligands were reported[1], and the exchange reactions of these and related 1,2-dithiolenes were studied with voltammetric techniques $[1,2]$.

Tris complexes with mixed 1,1- and 1,2-dithiolene ligands were also prepared and investigated recently $[3,4]$.

In the course of investigating mixed metal bis-complexes we found electron transfer series in $\mathrm{Ni}, \mathrm{Cu}$ and $\mathrm{Au}$ complexes containing an 1,2- as well as an 1,1-dithiolato ligand, $M\left(\mathrm{~S}_{2} \mathrm{C}_{2}(\mathrm{CN})_{2}\right)\left(\mathrm{S}_{2} \mathrm{CNbu}_{2}\right)^{2}$, with $z=-1$ and 0 [5].

The present paper describes the results of the voltammetric studies made on a series of mixed complexes derived from the same and some related sulfur donor ligands [6].

\section{RESULTS AND DISCUSSION}

\section{Preparations}

Analytical data for the newly prepared complexes correspond with the formulas given (Table 1). Colours, melting points and conductances are given in Table 2.

$$
\text { *Part-I. Ref. [5]. }
$$

1. A. Davison, J. A. McCleverty, E. T. Shawl and E. J. Wharton, J. Am. chem. Soc. 89, 830 (1967).

2. A. L. Balch, Inorg. Chem. 10, 388 (1971).

3. L. H. Pignolet, R. A. Lewis and R. H. Holm, J. Am. chem. Soc. 93, 360 (1971).

4. J. A. McCleverty, D. G. Orchard and K. Smith, J. chem. Soc., 707 (1971).

5. J. G. M. van der Linden and H. G. J. van de Roer, Inorg. Chim. Acta, 5, 254 (1971).

6. The following abbreviations are used:

$m n t=$ maleonitrile dithiolate $=\mathrm{S}_{2} \mathrm{C}_{2}(\mathrm{CN})_{2}$

$\mathbf{R}_{2} d t c=\mathbf{N}, \mathbf{N}$-di-alkyl(aryl)dithiocarbamate $=\mathbf{S}_{2} \mathrm{CNR}_{2}$

etxan $=$ O-ethylxanthate $=\mathrm{S}_{2}$ COet

$c d c=\mathrm{N}$-cyanodithiocarbimate $=\mathrm{S}_{2} \mathrm{CNCN}$ 
Table 1. Analytical data

$\% \mathrm{C} \quad \% \mathrm{H} \quad \% \mathrm{~N} \quad \%$ Metal

Complex found calc. found calc. found calc. found calc. found calc.

\begin{tabular}{|c|c|c|c|c|c|c|c|c|c|c|}
\hline $\mathrm{bu}_{4} \mathrm{NNi}(m n t)\left(e t_{2} d t c\right)$ & $51 \cdot 0$ & $50 \cdot 93$ & $7 \cdot 9$ & $7 \cdot 86$ & $9 \cdot 5$ & $9 \cdot 50$ & & & $10 \cdot 0$ & 9.95 \\
\hline $\mathrm{bu}_{4} \mathrm{NNi}(m n t)\left(p h_{2} d t c\right)$ & $57 \cdot 6$ & $57 \cdot 80$ & $6 \cdot 6$ & $6 \cdot 76$ & $8-2$ & $8 \cdot 17$ & & & $8 \cdot 7$ & $8 \cdot 56$ \\
\hline $\mathrm{Ni}(m n t)\left(b u_{2} d t c\right)$ & $38 \cdot 8$ & $38 \cdot 72$ & $4 \cdot 5$ & $4 \cdot 50$ & $10 \cdot 3$ & $10 \cdot 42$ & & & $14 \cdot 9$ & $14 \cdot 58$ \\
\hline $\mathrm{Ni}(m n t)\left(p h_{2} d t c\right)$ & $44 \cdot 5$ & $46 \cdot 07$ & $2 \cdot 3$ & $2 \cdot 27$ & $8 \cdot 5$ & $9 \cdot 48$ & $26 \cdot 6$ & $28 \cdot 94$ & $13 \cdot 3$ & $13 \cdot 25$ \\
\hline $\mathrm{et}_{4} \mathrm{NNi}($ mnt $)($ etxan $)$ & $40 \cdot 3$ & $40 \cdot 01$ & $5 \cdot 6$ & $5 \cdot 60$ & $9 \cdot 4$ & $9 \cdot 33$ & $27 \cdot 8$ & $28 \cdot 48$ & $13 \cdot 5$ & 13.04 \\
\hline$\left[\mathrm{pr}_{4} \mathrm{~N}\right]_{2} \mathrm{Ni}(m n t)(c d c)$ & $52 \cdot 2$ & $52 \cdot 38$ & $8 \cdot 2$ & $8 \cdot 20$ & $12 \cdot 0$ & $12 \cdot 20$ & $18 \cdot 3$ & $18 \cdot 60$ & $8 \cdot 4$ & $8 \cdot 54$ \\
\hline $\mathrm{bu}_{4} \mathrm{NCu}(m n t)\left(e t_{2} d t c\right)$ & $49 \cdot 5$ & $50 \cdot 51$ & $7 \cdot 8$ & $7 \cdot 79$ & $9 \cdot 3$ & $9 \cdot 43$ & & & & \\
\hline $\mathrm{bu}_{4} \mathrm{NCu}(m n t)\left(p h_{2} d t c\right)$ & $57 \cdot 0$ & $57 \cdot 40$ & $6 \cdot 8$ & $6 \cdot 71$ & $8 \cdot 7$ & $8 \cdot 11$ & & & & \\
\hline $\mathrm{Cu}(m n t)\left(e t_{2} d t c\right)$ & $30 \cdot 2$ & $30 \cdot 71$ & $2 \cdot 8$ & $2 \cdot 86$ & $11 \cdot 5$ & $11 \cdot 96$ & & & & \\
\hline $\mathrm{Cu}(m n t)\left(p h_{2} d t c\right)$ & $46 \cdot 2$ & $45 \cdot 57$ & $2 \cdot 4$ & $2 \cdot 25$ & $8 \cdot 0$ & $9 \cdot 38$ & & & & \\
\hline $\mathrm{bu}_{4} \operatorname{NPd}(m n t)\left(b u_{2} d t c\right)$ & $50 \cdot 4$ & $50 \cdot 23$ & $7 \cdot 7$ & $7 \cdot 85$ & $8 \cdot 2$ & $8 \cdot 08$ & $18 \cdot 3$ & $18 \cdot 93$ & $15 \cdot 3$ & $15 \cdot 34$ \\
\hline$\left[\mathrm{bu}_{4} \mathbf{N}\right]_{2} \mathrm{Pd}(m n t)(c d c)$ & $54 \cdot 7$ & $53 \cdot 84$ & $8 \cdot 2$ & $8 \cdot 56$ & $10 \cdot 0$ & $9 \cdot 91$ & & & $12 \cdot 4$ & $12 \cdot 55$ \\
\hline $\mathrm{bu}_{4} \mathrm{NPt}(m n t)\left(b u_{2} d t c\right)$ & $44 \cdot 8$ & $44 \cdot 53$ & $7 \cdot 0$ & $6 \cdot 95$ & $7 \cdot 4$ & $7 \cdot 16$ & & & $25 \cdot 2$ & $24 \cdot 94$ \\
\hline $\mathrm{Au}(m n t)\left(e t_{2} d t c\right)$ & $22 \cdot 4$ & $22 \cdot 27$ & $2 \cdot 2$ & $2 \cdot 07$ & $8 \cdot 8$ & $8 \cdot 66$ & $26 \cdot 4$ & $26 \cdot 25$ & $40 \cdot 4$ & $40 \cdot 58$ \\
\hline $\mathrm{Au}(m n t)\left(p h_{2} d t c\right)$ & $35 \cdot 2$ & $35 \cdot 11$ & $1 \cdot 7$ & $1 \cdot 73$ & $7 \cdot 3$ & $7 \cdot 23$ & & & & \\
\hline
\end{tabular}

The reported [5] ligand exchange reaction between nickel bis-(1,2-dithiolato) and nickel bis-(dithiocarbamato) complexes have now been extended to prepare the compounds $M(m n t)\left(\mathrm{R}_{2} d t c\right)^{-}$with $M=\mathrm{Cu}, \mathrm{Pd}$ and $\mathrm{Pt}$. Also $\mathrm{Ni}(\text { etxan })_{2}$

Table 2. Physical properties of the prepared complexes

\begin{tabular}{llccc}
\hline \multicolumn{1}{c}{ Complex } & \multicolumn{1}{c}{ Colour } & $\begin{array}{c}\text { m.p. } \\
{ }^{\circ} \mathrm{C}\end{array}$ & $\begin{array}{c}\Lambda_{\dagger}^{\dagger} \\
\left(\mathrm{cm}^{2} \Omega^{-1} M^{-1}\right)\end{array}$ & $\begin{array}{c}\nu_{\mathrm{CN}} \\
\left(\mathrm{cm}^{-1}\right)\end{array}$ \\
\hline $\mathrm{bu}_{4} \mathrm{NNi}(m n t)\left(e t_{2} d t c\right)$ & green & 137 & $20 \cdot 2$ & 1520 \\
$\mathrm{bu}_{4} \mathrm{NNi}(m n t)\left(b u_{2} d t c\right)^{*}$ & green & 121 & $18 \cdot 9$ & 1512 \\
$\mathrm{bu}_{4} \mathrm{NNi}(m n t)\left(p h_{2} d t c\right)$ & green & 163 & $18 \cdot 9$ & 1377 \\
$\mathrm{Ni}(m n t)\left(b u_{2} d t c\right)$ & blackgreen & 230 & & 1530 \\
$\mathrm{Ni}(m n t)\left(p h_{2} d t c\right)$ & black & $>360$ & & 1420 \\
$\mathrm{et}_{4} \mathrm{NNi}(m n t)(e t x a n)$ & green & 151 & $28 \cdot 2$ & \\
{$\left[\mathrm{pr}_{4} \mathrm{~N}\right]_{2} \mathrm{Ni}(m n t)(c d c)$} & brown & 207 & $52 \cdot 4$ & \\
$\mathrm{bu}_{4} \mathrm{NCu}(m n t)\left(e t_{2} d t c\right)$ & darkbrown & 110 & $20 \cdot 3$ & 1502 \\
$\mathrm{bu}_{4} \mathrm{NCu}(m n t)\left(b u_{2} d t c\right)^{*}$ & brown & 93 & $20 \cdot 0$ & 1480 \\
$\mathrm{bu}_{4} \mathrm{NCu}(m n t)\left(p h_{2} d t c\right)$ & brown & $110 \mathrm{dec}$ & $22 \cdot 3$ & 1370 \\
$\mathrm{Cu}(m n t)\left(e t_{2} d t c\right)$ & darkgreen & $>360$ & & 1570 \\
$\mathrm{Cu}(m n t)\left(b u_{2} d t c\right)^{*}$ & darkgreen & $>360$ & & 1550 \\
$\mathrm{Cu}(m n t)\left(p h_{2} d t c\right)$ & darkbrown & $>360$ & & 1390 \\
$\mathrm{bu}_{4} \mathrm{NPd}(m n t)\left(b u_{2} d t c\right)$ & yellow & 117 & $21 \cdot 8$ & 1518 \\
{$\left[\mathrm{bu}{ }_{4} \mathrm{~N}\right]_{2} \mathrm{Pd}(m n t)(c d c)$} & brownyellow & 114 & $53 \cdot 8$ & \\
$\mathrm{bu}_{4} \mathrm{NPt}(m n t)\left(b u_{2} d t c\right)$ & brown & 122 & $22 \cdot 8$ & 1523 \\
$\mathrm{Au}(m n t)\left(e t_{2} d t c\right)$ & green & 267 & & 1545 \\
$\mathrm{Au}(m n t)\left(b u_{2} d t c\right)^{*}$ & green & 188 & & 1555 \\
$\mathrm{Au}(m n t)\left(p h_{2} d t c\right)$ & green & 310 & & 1438 \\
\hline
\end{tabular}

*Ref. [5].

fIn nitrobenzene at roomtemperature $\left(5 \cdot 10^{-4}\right.$ molar solutions $)$. For a $1: 1$ electrolyte $\Lambda \sim 15-30$, for a $2: 1$ electrolyte $\Lambda \sim 45-65 \mathrm{~cm}^{2} \Omega^{-1} M^{-1}$. 
reacted readily with $\mathrm{Ni}(m n t)_{2}{ }^{2-}$ forming $\mathrm{Ni}(m n t)\left(\right.$ etxan) ${ }^{-}$. Not only with these dithioacid complexes but also with 1,1-dithiolato complexes the $M(m n t)_{2}{ }^{2-}$ complexes showed these ligand exchange reactions. In this way the $M(m n t)(c d c)^{2-}$ complexes $(M=\mathrm{Ni}$ and $\mathrm{Pd})$ were obtained. The platinum complexes however, $\mathrm{Pt}(m n t)_{2}{ }^{2-}$ and $\mathrm{Pt}(c d c)_{2}{ }^{2-}$, showed no exchange reaction, even after boiling in acetonitrile for 5 days. This is in agreement with observations made for platinum dithiolenes, which showed no scrambling reactions even after 30 days [2]. The exchange reactions between metal complexes both derived from dithioacids i.e., $\mathrm{Ni}\left(\mathrm{R}_{2} d t c\right)_{2}$ and $\mathrm{Ni}(\text { etxan })_{2}$ proceeded so slowly, that no mixed complex could be isolated so far.

Voltammetric measurements indicated (vide infra) that oxidation of some of the herein described complexes could be successful, in consequence of the reported half-wave potential for the oxidation of $\mathrm{Cu}(d t c)_{2}(0.47 \mathrm{~V} \mathrm{vs}$. SCE) and the successful synthesis of $\mathrm{Cu}(d t c)_{2} \mathrm{I}_{3}[7]$.

The oxidation of $\mathrm{Ni}(m n t)\left(\mathbf{R}_{2} d t c\right)^{-}$led to green black products analysing as $\mathrm{Ni}(m n t)\left(\mathrm{R}_{2} d t c\right)^{0}(R=$ bu or $\mathrm{ph})$. Both complexes showed in the esr spectrum a single line as can be expected for paramagnetic nickel $(I=0)$ compounds. The high values observed for the $\mathrm{C}-\mathrm{N}$ stretching frequencies in the i.r. spectrum (Table 2) indicated also compounds with the metal in a high oxidation state. This is generally observed for oxidized dithiocarbamato complexes [8].

The brown $\left[\mathrm{pr}_{4} \mathrm{~N}\right]_{2} \mathrm{Ni}(m n t)(c d c)$ could be oxidized with iodine to red products, which also showed a one-line e.s.r. spectrum, but no analytically pure sample was obtained so far. Further investigations on these nickel(III) complexes are in progress.

The $\mathbf{C}-\mathbf{N}$ stretching absorption, usually found in the range $1570-1400 \mathrm{~cm}^{-1}$ is a much discussed property of dithiocarbamato complexes. The values of $\nu_{\mathrm{CN}}$ for $M(m n t)\left(\mathbf{R}_{2} d t c\right)^{z}$ compounds, given in Table 2 , decreased in the order $\mathbf{R}=m e>$ et $>b u>p h$, also observed previously for bis(chelates) [9].

\section{Voltammetric Study}

The measured half-wave potentials are summarised in Table 3. The measurements are carried out in dichloromethane solutions, using a rotating platinum electrode as the indicator electrode and a saturated calomel electrode as the reference. As a reversibility criterion the values of $E_{3 / 4}-E_{1 / 4}$ were taken. The halfwave potentials obtained for the mixed complexes are generally in the middle between those for the unmixed complexes.

The influence of the alkyl(aryl) group in the bis $(d t c)$ complexes on the $E_{1 / 2}$ values is small but significant. It is remarkable that the sequence for $E_{1 / 2}$ values phenyl $>e t>b u$ is reversed for the $\mathrm{Ni}\left(\mathbf{R}_{2} d t c\right)_{2}$ compounds, compared with the other bis $(d t c)$ complexes. In this group of bis $(d t c)$ complexes only the copper compounds showed a reversible behaviour. This is reflected in a remarkable way in the preparative oxidation of $d t c$ complexes, only the copper complex giving a

7. H. C. Brinkhoff, Rec. Trav. Chim. 90, 377 (1971).

8. (a). P. T. Beurskens, J. A. Cras and J. J, Steggerda, Inorg. Chem, 7, 810 (1968); (b), H. C. Brinkhoff, Thesis, Nijmegen, 1970.

9. J. G. M. yan der Linden, Rec. Trav. Chim. 90, 1027 (1971). 
Table 3. Voltammetric data in dichloromethane solutions*

\begin{tabular}{|c|c|c|c|c|c|c|c|}
\hline Complex & Process & $\begin{array}{l}E_{1 / 2} \\
(\mathrm{~V})\end{array}$ & $\begin{array}{c}E_{3 / 4}-E_{1 / 4} \\
\quad(\mathrm{mV})\end{array}$ & Complex & Process & $\begin{array}{l}E_{1 / 2} \\
(\mathrm{~V})\end{array}$ & $\begin{array}{c}E_{3 / 4}-E_{1 / 4} \\
\quad(\mathrm{mV})\end{array}$ \\
\hline $\mathrm{Ni}(\text { etxan })_{2}$ & $0 \rightarrow+1$ & 0.88 & 80 & $\mathrm{Cu}\left(p h_{2} d t c\right)_{2}$ & $0 \rightarrow+1$ & 0.52 & 62 \\
\hline $\mathrm{Ni}(m n t)(e t x a n)^{-}$ & $-1 \rightarrow 0$ & 0.86 & 109 & $\mathrm{Cu}\left(e t_{2} d t c\right)_{2}$ & $0 \rightarrow+1$ & 0.50 & 62 \\
\hline $\mathrm{Ni}\left(b u_{2} d t c\right)_{2}$ & $0 \rightarrow+1$ & 0.79 & 152 & $\mathrm{Cu}\left(b u_{2} d t c\right)_{2}$ & $0 \rightarrow+1$ & 0.47 & 60 \\
\hline $\mathrm{Ni}\left(e t_{2} d t c\right)_{2}$ & $0 \rightarrow+1$ & 0.77 & 148 & $\operatorname{Cu}(m n t)\left(p h_{2} d t c\right)$ & $0 \rightarrow-1$ & 0.34 & 84 \\
\hline $\mathrm{Ni}\left(p h_{2} d t c\right)_{2}$ & $0 \rightarrow+1$ & 0.75 & 200 & $\mathrm{Cu}(m n t)\left(b u_{2} d t c\right)$ & $0 \rightarrow-1$ & 0.33 & 68 \\
\hline $\operatorname{Ni}(m n t)\left(p h_{2} d t c\right)^{-}$ & $-1 \rightarrow 0$ & 0.48 & 84 & $\mathrm{Cu}(m n t)\left(e t_{2} d t c\right)$ & $0 \rightarrow-1$ & 0.33 & 68 \\
\hline $\operatorname{Ni}(m n t)\left(b u_{2} d t c\right)^{-}$ & $-1 \rightarrow 0$ & $0 \cdot 46$ & 68 & & & & \\
\hline $\mathrm{Ni}(m n t)\left(e t_{2} d t c\right)^{-}$ & $-1 \rightarrow 0$ & 0.46 & 62 & $\operatorname{Au}\left(p h_{2} d t c\right)_{2}{ }^{+}$ & $+1 \rightarrow 0$ & $-0 \cdot 19$ & 81 \\
\hline \multirow[t]{2}{*}{$\mathrm{Ni}(m n t)(c d c)^{2-}$} & $-2 \rightarrow-1$ & $0-38$ & 58 & $\mathrm{Au}\left(m e_{2} d t c\right)_{2}^{+}$ & $+1 \rightarrow 0$ & -0.22 & 75 \\
\hline & & & & $\mathrm{Au}\left(e t_{2} d t c\right)_{2}{ }^{+}$ & $+1 \rightarrow 0$ & -0.26 & 72 \\
\hline $\operatorname{Pd}\left(b u_{2} d t c\right)_{2}$ & $0 \rightarrow+1$ & $1 \cdot 21$ & 140 & $\mathrm{Au}\left(p r_{2} d t c\right)_{2}{ }^{+}$ & $+1 \rightarrow 0$ & $-0 \cdot 28$ & 77 \\
\hline $\operatorname{Pd}(m n t)\left(b u_{2} d t c\right)^{-}$ & $-1 \rightarrow 0$ & 0.71 & 56 & $\mathrm{Au}\left(b u_{2} d t c\right)_{2}{ }^{+}$ & $+1 \rightarrow 0$ & $-0 \cdot 29$ & 78 \\
\hline \multirow[t]{2}{*}{$\operatorname{Pd}(m n t)(c d c)^{2-}$} & $-2 \rightarrow-1$ & 0.60 & 58 & $\mathrm{Au}(m n t)\left(p h_{2} d t c\right)$ & $0 \rightarrow-1$ & -0.41 & 60 \\
\hline & & & & $\mathrm{Au}(m n t)\left(e t_{2} d t c\right)$ & $0 \rightarrow-1$ & -0.45 & 60 \\
\hline $\operatorname{Pt}\left(b u_{2} d t c\right)_{2}$ & $0 \rightarrow+1$ & 0.92 & 240 & $\mathrm{Au}(m n t)\left(b u_{2} d t c\right)$ & $0 \rightarrow-1$ & -0.456 & 66 \\
\hline $\operatorname{Pt}(m n t)\left(b u_{2} d t c\right)^{-}$ & $-1 \rightarrow 0$ & 0.56 & 56 & & & & \\
\hline
\end{tabular}

${ }^{*}$ Vs. SCE using approx. $5 \cdot 10^{-4}$ molar solution with $0 \cdot 1 \mathrm{Mbu}_{4} \mathrm{NClO}_{4}$ as the supporting electrolyte. 
reaction product of the same stoichiometry $\mathrm{Cu}(d t c)_{2}{ }^{+}$, nickel[10], palladium and platinum[11] giving tris-complexes, $M(d t c)_{3}{ }^{+}$, with the metal in the oxidation state +4 .

In the mixed complexes, $M(m n t)\left(\mathbf{R}_{2} d t c\right)^{z}$, the influence of the alkyl(aryl) group vanished almost totally. The $\mathrm{M}(m n t)\left(\mathrm{R}_{2} d t c\right)^{z}(z=0$ or $-1, M=\mathrm{Ni}, \mathrm{Cu}$, $\mathrm{Pd}, \mathrm{Pt}, \mathrm{Au})$ and $M(m n t)(c d c)^{2-}(M=\mathrm{Ni}, \mathrm{Pd})$ complexes showed a reversible redox behaviour. This could be confirmed by the synthesis of $\mathrm{Ni}(m n t)\left(\mathrm{R}_{2} d t c\right)$ and $\mathrm{Cu}(m n t)\left(\mathrm{R}_{2} d t c\right)$.

A comparison of the oxidation waves for the mixed nickel complexes $\mathrm{Ni}(m n t)(\mathrm{L})^{z}$, showed that there was a significant effect arising from the ligand $\mathrm{L}$. Thus the $E_{1 / 2}$ values became more positive in the sequence $\mathrm{L}=c d c<\mathrm{R}_{2} d t c<$ etxan. A corresponding order was found shortly for cobalt and iron tris-complexes with the same and some related sulfur donor ligands [4].

The oxidation potentials for the mixed and unmixed complexes are dependent on $M$ (Table 4). The order of $E_{1 / 2}$ values for $M\left(\mathrm{R}_{2} d t c\right)_{2}$ and $M(m n t)\left(\mathrm{R}_{2} d t c\right)^{-}$ complexes $\mathrm{Cu}<\mathrm{Ni}<\mathrm{Pt}<\mathrm{Pd}$ is however not valid for the oxidation potentials of $M(m n t)_{2}{ }^{2-}$ compounds.

Table 4. Polarographic halve-wave potentials for the reaction

$$
\mathrm{ML}_{1} \mathbf{L}_{2}^{z} \rightarrow \mathrm{ML}_{1} \mathrm{~L}_{2}^{z+1}+\mathrm{e}
$$

\begin{tabular}{lccccc}
\hline & $\mathrm{Cu}$ & $\mathrm{Ni}$ & $\mathrm{Pt}$ & $\mathrm{Pd}$ & $\mathrm{Au}$ \\
$M\left(b u_{2} d t c\right)_{2}$ & 0.47 & 0.75 & 0.92 & 1.21 & -0.29 \\
$M(m n t)\left(b u_{2} d t c\right)^{-}$ & 0.33 & 0.46 & 0.56 & 0.71 & -0.46 \\
$M(m n t)(c d c)^{2-}$ & & 0.38 & & 0.60 & \\
$M(m n t)_{2}{ }^{2-}$ & 0.23 & 0.19 & 0.20 & 0.41 & -0.61 \\
\hline
\end{tabular}

In $\mathrm{CH}_{2} \mathrm{Cl}_{2}$ vs. SCE.

\section{EXPERIMENTAL}

\section{Starting materials}

The starting products were synthesised as described in the literature: $\left(\mathrm{bu}_{4} \mathrm{~N}\right)_{2} M(m n t)_{2}$ with $\mathrm{Ni}, \mathrm{Cu}$, Pd, Pt [12], $\left(b_{4} \mathbf{N}\right)_{2} M(c d c)$, with $M=N i, \operatorname{Pd}, \operatorname{Pt}[13], \mathbf{N i}(e t x a n)_{2}$ [14], $\operatorname{Au}\left(\mathbf{R}_{2} d t c\right)_{2} \operatorname{Br}[19] . M\left(\mathbf{R}_{2} d t c\right)_{2}$ were prepared by general known methods [15].

\section{Preparation of the complexes}

The $\left(\mathrm{bu}_{4} \mathrm{~N}\right) M(m n t)\left(\mathrm{R}_{2} d t c\right),\left(\mathrm{R}_{4} \mathrm{~N}\right)_{2} M(m n t)(c d c)$ and $\left(\mathrm{et}_{4} \mathrm{~N}\right) \mathrm{Ni}(m n t)($ etxan) were synthesised from their unmixed bis(chelates) by a procedure similar to that described for bu ${ }_{4} \mathrm{NNi}(m n t)\left(\mathrm{bu}_{2} d t c\right)$ [5].

$\mathrm{Cu}(m n t)\left(\mathbf{R}_{2} d t c\right), \mathrm{Au}(m n t)\left(\mathbf{R}_{2} d t c\right)$ were prepared from an equimolar mixture of $\mathrm{Br}_{2} M\left(\mathbf{R}_{2} d t c\right)$ and $\mathrm{Na}_{2} m n t$ by a procedure similar to that described for $\mathrm{Cu}(m n t)\left(\mathrm{bu}_{2} d t c\right)$ [5].

$\mathrm{Ni}(m n t)\left(\mathrm{bu}_{2} d t c\right)$ was prepared by oxidation of the corresponding nickel(II) complex $(2,0 \mathrm{~g}$ in $400 \mathrm{ml}$ $\left.\mathrm{CH}_{2} \mathrm{Cl}_{2}\right)$ by adding in $15 \mathrm{~min}$ an excess iodine $(1,6 \mathrm{~g}$ in $75 \mathrm{ml}$ of the same solvent). The solvent was evaporated in vacuo and the residue was thoroughly washed with ethanol, until iodine free. The

10. H. C. Brinkhoff, J. A. Cras, J. J. Steggerda and J. Willemse, Rec. Trav. Chim. 88, 633 (1969).

11. J. Willemse, personal communication, to be published.

12. A. Davison and R. H. Holm, Inorg. Synth. 10, 8 (1967).

13(a). J. P. Fackler and D. Coucouvanis, J. Am. chem. Soc. 88, 3913 (1966); (b) F. A. Cotton and J. A. McCleverty, Inorg. Chem. 6, 229 (1967).

14. D. Coucouvanis and J. P. Fackler, Inorg. Chem. 6, 2047 (1967).

15. D. Coucouvanis, Prog. Inorg. Chem. 11, 233 (1970) and references therein. 
product was dissolved in $30 \mathrm{ml}$ hot chloroform, the solution was filtered, and to the filtrate $50 \mathrm{ml}$ of diethyl ether was added. On cooling green black crystals were obtained in 70 per cent yield.

$\mathrm{Ni}(m n t)\left(p h_{2} d t c\right)$ was obtained as a black precipitate from the oxidation of bu ${ }_{4} \mathrm{NNi}(m n t)\left(p h_{2} d t c\right)$ with iodine in $\mathrm{CH}_{2} \mathrm{Cl}_{2}$. The product was purified by repeated washing with acetone, and at least once with diethyl ether. After drying a black powder resulted. Yield 75 per cent.

\section{Physical measurements}

Voltammetric measurements in dichloromethane solutions were made with a Metrohm Polarecord E 261 with a Metrohm E 446 iR compensator equipped with three electrode geometry.

Conductivity measurements in nitrobenzene were carried out as described previously [16].

I.R. spectra were measured on a Perkin Elmer 257 spectrophotometer using the $\mathrm{KBr}$ disc technique.

Acknowledgements - The author wishes to thank Prof. J. J. Steggerda for the critical reading of the manuscript, Mr. P. J. Koonen for technical assistance and Mr. H. A. S. Jorna and Mr. C. A. G. Weenen for their contributions to these investigations.

16. P. T. Beurskens, H. J. A. Blaauw, J. A. Cras and J. J. Steggerda, Inorg. Chem. 7, 805 (1968). 